\title{
Canopy management and water use efficiency in vineyards under Mediterranean semiarid conditions
}

\author{
Mario de la Fuente, Rubén Linares, and José Ramón Lissarrague \\ Departamento de Producción Agraria, Grupo de Investigación en Viticultura, Universidad Politécnica de Madrid, Ciudad \\ Universitaria s/n, 28040 Madrid, Spain
}

\begin{abstract}
One of the main objectives in Mediterranean vineyards is the water use efficiency due to its scarcity. During the growing season, total available water is significantly lower than the evaporative demand, being this a limiting factor for quality production. Beside other factors, the choice of an adequate training system can help mitigate this negative effect in regard with soil-plant hydric consumption. The use of porous systems can help plants establish a better leaf distribution inside the clusters area, providing more space and enhancing certain physiological processes, both in leaves and berries (de la Fuente et al., 2013), and causing a better utilization of natural resources.

Water consumption, dynamics and hydric relations in plants (water potential) and soil (soil water tension and capacity) have been studied on three different systems: sprawl system with 12 shoots $\mathrm{m}^{-1}(\mathrm{~S} 1)$; sprawl system with 18 shoots $\mathrm{m}^{-1}$ (S2) and vertical positioned system or VSP with 12 shoots $\mathrm{m}^{-1}$ (VSP1). Yield, dry matter partitioning and berry and must composition have also been obtained at the maturity stage.

The main objective of this study was to show the differences in consumption and water use efficiency due to different canopy managements, and to quantify these effects on yield, berry and must composition.

The results showed that the vertical system (VSP1) benefited less from total available water at medium level (20; 30 and $50 \mathrm{~cm})$ in the profile soil (0.5-1.5\% available water vol.), in comparison with non-positioned and free systems (S1 and S2). On the other hand, S1 and S2 treatments caused more stress to the plant at midday from flowering to veraison (8-10\%), but not during ripening. Sprawl system (S1) helps produce more balanced plants compared to VSP1, because it obtains higher number (and weight) of main leaves by shoot, increasing the number of secondary shoots and maximizing the canopy volume. No differences were observed in the number of clusters, berry size or yield between VSP1 and S1, but higher crop load treatment (S2) showed an evident yield increase (16\%) at harvest.

Berry and must composition did not change (Brix, $\mathrm{pH}$ and total acidity) much, while the composition of anthocyanins improved with low exposure and non-positioned systems (S1 and S2).

In addition, both positive effects of sprawl treatments (crop load and training system) resulted in better yield and quality in Mediterranean semiarid conditions under the same inputs (sun, water and soil), causing higher efficiency of natural resources.
\end{abstract}

\section{Introduction}

Water is likely to be sufficient for food production in 2050, but increased competition means two-thirds of the world will be affected by water scarcity [1]. One of the main objectives nowadays in Mediterranean vineyards is the water use efficiency due to this problem. During the growing season, total available water is significantly lower than the evaporative demand, being this a limiting factor for quality production.

Moreover, the information available refers to the effect of water distribution pattern in grapevines is even scarcer, despite it is known to affect the shape of the wetted soil zone, modifying the root system development and its function [2]. Grape roots appeared to have phenotypically distinct stages of development, but the functional states of these stages were unknown [3].

Training and trellising system are one of the most relevant factors in order to manage the water plant consumption [4,5]. The placing of leaves, brunches and clusters inside the plant can modulate several processes like solar radiation, light interception, transpiration or photosynthesis among others, through modifying some relevant variables like temperature or time of sun exposure $[6,7]$.

Due to this, vegetative or root development and reproductive yield can be modified by water consumption and sun exposure among other factors. Shoot growth may be more strongly affected by water limitations than its reproductive growth, but also, roots development can be limited. These limitations could appear especially in warm, dry climates or under water scarcity conditions, mainly when reproductive demands for carbon were at its highest and physical conditions limiting their development during the cycle $[8,9]$.

Therefore, an adequate balance among crop load, training - trellising system and water management should be required in warm climates as a key point in order to assess the expected quality for grapes and wine.

The main objective of the present work was to examine the effects of three different training systems on water consumption (relations between soil-plant) and also, their effect on yield and grape quality under Mediterranean warm climate conditions. 


\section{Materials and methods}

This field experiment was conducted (2006) in an experimental trial in Toledo (Spain), on a fine clay-sandy soil (Palexeralf, Soil Survey Staff, 2003) with a $50 \mathrm{~cm}$ depth clay superficial horizon (50-55\% of clay). The weather conditions were typical for Mediterranean semiarid climate (Papadakis, 1966). The cultivar was Syrah, grafted on 110R and spaced $1.2 \mathrm{~m}$, in the NW-SE $\left(+8.3^{\circ}\right.$ to West) orientated rows with $2.7 \mathrm{~m}$ between rows. Irrigation system drippers $\left(3 \mathrm{l} \mathrm{h}^{-1}\right)$ were spaced $1.2 \mathrm{~m}$ along the planting line and the amount applied (248 mm during total cycle) was equal for all treatments. Climatic conditions of this year were extremely warm. Differences can be observed mainly in accumulated growing degree days (2525 GDD), low rainfall $(168 \mathrm{~mm})$ and in evapotranspiration reference $(1211.1 \mathrm{~mm}$; Eto) index too. Trial was designed with three treatments placed into four blocks at random and each experimental plot consisted of 20 control plants, separated by rows and vines edge. The three examined treatments, in order to assess the impact of training system and crop load, were: (i) VSP1, Espaldera or vertical positioned system (VSP) with 12 shoots/m of crop load, (ii) S1, Sprawl with 12 shoots $/ \mathrm{m}$ of crop load and (iii) S2, Sprawl with 18 shoots/m of crop load. (50\% crop load more than VSP1 and S1).Vines were spur pruned and trained in a bilateral cordon at the height of $1.40 \mathrm{~m}$. The sprawl system had a single couple vegetation wires from $0.4 \mathrm{~m}$ to the basal wire and they opened $0.6 \mathrm{~m}$ between wires. VSP system had a couple wires from $0.3 \mathrm{~m}$ to the basal wire and a higher wire at $1.5 \mathrm{~m}$ to basal wire.

Plant water status was estimated measuring leaf water potential at mid-day $\left(\psi_{12 \mathrm{~h}}\right)$ using a Scholander type pressure chamber (PMS, Portland, Oregon). At the same time, some leaves were covered with a plastic bag prior to -severing the petiole, gas flow was limited to $0.2 \mathrm{bar} \mathrm{s}^{-1}$ and the measurement was performed with in the 1-1.5 $\mathrm{min}$ after detaching the leaf from the plant. About 90-120 min before midday, other leaves were covered with an aluminum foil for measuring the stem water potential $\left(\psi_{\text {stem }}\right)$. All leaves chosen were of similar age and type but for $\psi_{12 \mathrm{~h}}$ leaves were well sun exposed and non-sun exposed for $\psi_{\text {stem }}[10,11]$. Measurements were carried out on 6 and 1 leaves ( $\psi_{12 \mathrm{~h}}$ and $\psi_{\text {stem }}$ respectively) per replicate at 3 phenological stages (fruitset, veraison, and end of ripening).

Total Available Water was calculated to be $96 \mathrm{~mm}$ using the Saxton-Rawls model [12], considering the texture properties of the two soil horizons observed in the rootexplored horizons. Soil water tension at three depths $(20,50$ and $80 \mathrm{~cm}$ ) was monitored weekly using Granular Matrix Sensors (GMS). Three sensors were placed (one for each depth level) in three replicates of each treatment. On the other hand, soil moisture content was monthly monitored by an encapsulated capacitance sensor (Diviner 2000, Sentek ${ }^{\odot}$ ) inserted in a continuous probe. Tubes were placed in three replicates of each treatment during the growth season.

Yield partitioning of dry matter was done by 8 samples of representative shoots per treatment, and were decomposed in: clusters, principal leaves, principal stem, secondary leaves and secondary stems. They were weighed separately in a scale COBOS $^{\circledR}$ S.A. model C-600-SX $( \pm 0.01 \mathrm{~g}$ sensibility), expressing fresh weight results. Then, $25 \%$ of the samples were dried in a stove (SELECTA $^{\circledR}$ model) until constant weight. Then, the dried ratio for each treatment was obtained and used to calculate the rest of partitioning data of each sample.

A reproductive yield study was done during the harvest $(30 / 08 / 2006)$ on ten previously selected plants for each treatment and block. Cluster number, average cluster weight, average berry weight and berry number per cluster and yield $\left(\mathrm{kg} \mathrm{m}^{-1}\right)$ were calculated and counted, and each cluster individually hand-harvested from each plant. A digital field balance (Jadever ${ }^{\circledR}$ JCA series; maximum capacity $60 \mathrm{~kg}$; accurate to $1 \mathrm{~g}$ ) was used for experimental data measurements. In addition, during the harvest a 100-berry sample per single plot was collected to follow 100-berries weight ( $\mathrm{g}), \mathrm{SST}\left({ }^{\circ} \mathrm{Brix}\right), \mathrm{pH}$ and phenol maturity, according to Glories (2001) method, so the final values corresponded to the harvest date of each year.

Finally, all data were analyzed by ANOVA with the statistical software SPSS v.15.0. Duncan's multiple range tests at $5 \%$ significance level were used to compare means among treatments.

\section{Results and discussion}

\subsection{Water consumption and soil hydric relations}

Leaf water potential was measured (Table 1) at fruit set and the weighted mean value for midday $\left(\psi_{12 \mathrm{~h}}\right)$ tended to show small differences between treatments. Under the same water availability conditions, the biggest difference appeared during veraison and with the stem water potential $\left(\psi_{\text {stem }}\right)$, causing to S2 the highest stress to the plant. For both water availabilities between veraison and harvest, the

Table 1. Leaf water potential at fruitset, veraison and harvest in 2006.

\begin{tabular}{|c|c|c|c|}
\hline \multirow{2}{*}{ Cycle } & \multirow[t]{2}{*}{ Treatment } & \multicolumn{2}{|c|}{ Leaf water potential (MPa) } \\
\hline & & $\psi_{12 \mathrm{~h}}$ & $\psi_{\text {stem }}$ \\
\hline \multirow{5}{*}{ Fruitset } & VSP1 & $-0.86 b$ & -0.60 \\
\hline & $\mathrm{S} 1$ & $-0.94 \mathrm{a}$ & -0.65 \\
\hline & S2 & $-0.95 \mathrm{a}$ & -0.65 \\
\hline & \multirow{2}{*}{$\begin{array}{c}\operatorname{EEM}^{1}\left(n_{1}=6\right) \\
\operatorname{Sig}^{2}\end{array}$} & 0.01 & 0.05 \\
\hline & & $*$ & NS \\
\hline \multirow{5}{*}{ Veraison } & VSP1 & -1.32 & $-0.99 b$ \\
\hline & $\mathrm{S} 1$ & -1.37 & $-1.06 \mathrm{~b}$ \\
\hline & S2 & -1.38 & $-1.14 \mathrm{a}$ \\
\hline & \multirow{2}{*}{$\begin{array}{c}\operatorname{EEM}^{1}\left(n_{2}=6\right) \\
\operatorname{Sig}^{2}\end{array}$} & 0.04 & 0.03 \\
\hline & & NS & $* *$ \\
\hline \multirow{5}{*}{ Harvest } & VSP1 & -1.34 & -1.03 \\
\hline & $\mathrm{S} 1$ & -1.48 & -1.03 \\
\hline & S2 & -1.58 & -1.14 \\
\hline & \multirow{2}{*}{$\begin{array}{c}\operatorname{EEM}^{1}\left(n_{2}=6\right) \\
\operatorname{Sig}^{2}\end{array}$} & 0.20 & 0.10 \\
\hline & & NS & NS \\
\hline
\end{tabular}

EEM: standard average error for $n=6$ samples per treatment.

${ }^{2}$ Sig: significant differences; $\mathrm{ns}$ and $* *$ means to there is no significant differences and $\mathrm{P}<0.01$ respectively. The values with the same letter are equal (T. Duncan).

$\mathrm{P}$-values were determined by analysis of variance. 
Table 2. Soil water tension at fruitset, veraison and harvest in 2006.

\begin{tabular}{|c|c|c|c|c|}
\hline \multirow{2}{*}{ Cycle } & \multirow[t]{2}{*}{ Treatment } & \multicolumn{3}{|c|}{ Soil water tension (MPa) } \\
\hline & & $20 \mathrm{~cm}$ & $50 \mathrm{~cm}$ & $80 \mathrm{~cm}$ \\
\hline \multirow{5}{*}{ Fruitset } & VSP1 & -0.16 & -0.15 & -0.03 \\
\hline & $\mathrm{S} 1$ & -0.20 & -0.14 & -0.02 \\
\hline & S2 & -0.17 & -0.11 & -0.05 \\
\hline & \multirow{2}{*}{$\begin{array}{c}\operatorname{EEM}^{1}\left(n_{1}=3\right) \\
\operatorname{Sig}^{2}\end{array}$} & 0.02 & 0.05 & 0.02 \\
\hline & & NS & NS & NS \\
\hline \multirow{5}{*}{ Veraison } & VSP1 & -0.02 & $-0.02 b$ & -0.14 \\
\hline & S1 & -0.06 & $-0.20 \mathrm{a}$ & -0.19 \\
\hline & S2 & -0.02 & $-0.20 \mathrm{a}$ & -0.16 \\
\hline & \multirow{2}{*}{$\begin{array}{c}\operatorname{EEM}^{1}\left(n_{2}=3\right) \\
\operatorname{Sig}^{2}\end{array}$} & 0.01 & 0.00 & 0.04 \\
\hline & & NS & $* * *$ & NS \\
\hline \multirow{5}{*}{ Harvest } & VSP1 & -0.01 & -0.06 & -0.07 \\
\hline & S1 & -0.10 & -0.20 & -0.06 \\
\hline & S2 & -0.01 & -0.07 & 0.00 \\
\hline & \multirow{2}{*}{$\begin{array}{c}\operatorname{EEM}^{1}\left(n_{2}=3\right) \\
\operatorname{Sig}^{2}\end{array}$} & 0.03 & 0.05 & 0.05 \\
\hline & & NS & NS & NS \\
\hline
\end{tabular}

${ }^{1}$ EEM: standard average error for $\mathrm{n}=3$ samples per treatment.

${ }^{2} \mathrm{Sig}$ : significant differences; ns and $* * *$ means to there is no significant differences and $\mathrm{P}<0.001$ respectively. The values with the same letter are equal (T. Duncan).

$\mathrm{P}$-values were determined by analysis of variance.

potential values reached during most of the ripening period correspond to severe stress according to Van Leeuwen et al. (2009), due to the severe climatic conditions in 2006. Even if there are not differences among treatments, S1 and

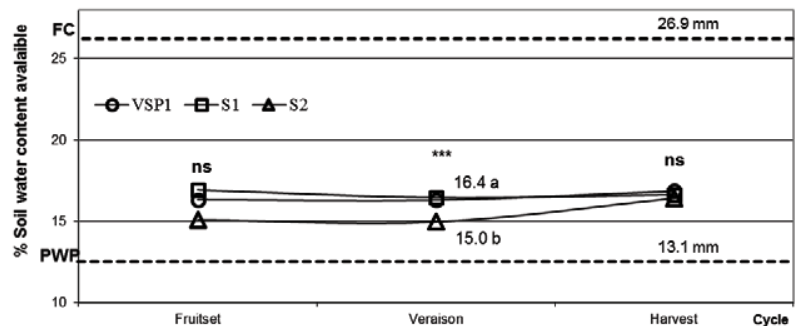

Figure 1. Average percentage of soil water content of three treatments between field capacity and permanent wilting point (soil conditions: $\% \mathrm{FC}=26.1$ and $\% \mathrm{PWP}=12.75)^{2}$.

${ }^{2}$ Sig: significant differences; ns and $* * *$ means to there is no significant differences and $P<0.001$ respectively. The values with the same letter are equal (T. Duncan).

$P$-values were determined by analysis of variance.

$\mathrm{S} 2$ tended to have a lower value related with VSP1, being under $-1.5 \mathrm{MPa}$, which could be a limiting factor for physiological processes $[9,13]$. These results are according to Dufourcq et al. (2005) trial, where the higher crop load caused a lower potentials [14] in the plants.

These effects can be related to the soil content water availability (Table 2). Main differences appears in veraison, where sprawl systems (S1 and S2) scored higher values of tension instead of VSP. It seems that sprawl systems could explore more extensively the soil profile during the hardest period with respect to drought (veraison). On the other hand, there were no differences at fruitset and the end of ripening (harvest).

Figure 1 shows the evolution of soil content water measured by capacity probe for all treatments. VSP1 and S1 presented an intermediate and equivalent moisture content between them, comparing with S2 values. S2 scored $1.5 \%$ less percentage of water content at veraison.

Table 3. Percentage of soil water content at fruitset, veraison and harvest in 2006 for each level of soil profile $(10-80 \mathrm{~cm})$.

\begin{tabular}{|c|c|c|c|c|c|c|}
\hline \multirow[t]{2}{*}{ Cycle } & \multirow[t]{2}{*}{ Treatment } & \multicolumn{5}{|c|}{ Deep $(\mathrm{cm})$} \\
\hline & & 10 & 20 & 30 & 40 & 80 \\
\hline \multirow{5}{*}{ Fruitset } & VSP1 & 15.46 & 16.57 & 16.82 & 17.05 & 17.24 \\
\hline & S1 & 16.55 & 16.83 & 16.77 & 16.99 & 17.11 \\
\hline & $\mathrm{S} 2$ & 15.50 & 15.84 & 16.07 & 16.62 & 17.34 \\
\hline & \multirow{2}{*}{$\begin{array}{c}\operatorname{EEM1}\left(\mathrm{n}_{1}=4\right) \\
\mathrm{Sig}^{2}\end{array}$} & 3.48 & 2.07 & 2.70 & 2.44 & 1.92 \\
\hline & & NS & NS & NS & NS & NS \\
\hline \multirow{5}{*}{ Veraison } & VSP1 & 15.19 & $16.58 \mathrm{a}$ & $16.86 \mathrm{a}$ & 17.04 & 17.29 \\
\hline & $\mathrm{S} 1$ & 14.98 & $15.99 \mathrm{ab}$ & $16.02 \mathrm{ab}$ & 16.37 & 16.49 \\
\hline & $\mathrm{S} 2$ & 14.62 & $15.63 b$ & $15.87 \mathrm{~b}$ & 16.56 & 17.39 \\
\hline & \multirow{2}{*}{$\begin{array}{c}\operatorname{EEM}^{1}\left(n_{2}=4\right) \\
\operatorname{Sig}^{2}\end{array}$} & 3.57 & 1.30 & 1.76 & 2.08 & 4.08 \\
\hline & & NS & $* *$ & $*$ & NS & NS \\
\hline \multirow{5}{*}{ Harvest } & VSP1 & 15.34 & 16.58 & 16.92 & 17.29 & 17.48 \\
\hline & S1 & 15.30 & 16.32 & 16.43 & 16.75 & 17.12 \\
\hline & $\mathrm{S} 2$ & 14.79 & 15.81 & 16.06 & 16.80 & 17.48 \\
\hline & \multirow{2}{*}{$\begin{array}{c}\operatorname{EEM}^{1}\left(n_{2}=4\right) \\
\operatorname{Sig}^{2}\end{array}$} & 3.56 & 1.68 & 2.47 & 2.06 & 2.68 \\
\hline & & NS & NS & NS & NS & NS \\
\hline
\end{tabular}

${ }^{2}$ Sig: significant differences; ns, $*$ and ** means to there is no significant differences or $P<0.05$ and $P<0.01$ respectively. The values with the same letter are equal (T. Duncan). $P$-values were determined by analysis of variance. 
Table 4. Dry matter partitioning for three treatments.

\begin{tabular}{|c|c|c|c|c|c|c|}
\hline \multirow{2}{*}{ Treatment } & \multicolumn{3}{|c|}{ Principal (g/shoot) } & \multicolumn{3}{|c|}{ Secondary (g/shoot) } \\
\hline & Stem & Leaves & Clusters & Stem & Leaves & Clusters \\
\hline VSP1 & 46.9 & $16,2 b$ & 131.3 & 3.4 & $7,9 \mathrm{~b}$ & 0.9 \\
\hline S1 & 44.8 & $21,1 \mathrm{a}$ & 142.7 & 1.9 & $15,6 \mathrm{a}$ & 1.8 \\
\hline $\mathrm{S} 2$ & 25.9 & $20,8 \mathrm{a}$ & 83.8 & 2.3 & $5,7 \mathrm{~b}$ & 0 \\
\hline $\operatorname{EEM}^{1}(n=8)$ & 7.02 & 2.27 & 30.32 & 0.61 & 1.76 & 0.4 \\
\hline Sig $^{2}$ & ns & $*$ & ns & ns & $* *$ & ns \\
\hline \multirow{2}{*}{ Treatment } & \multicolumn{3}{|c|}{ Principal $\left(\mathrm{n}^{\mathbf{0}}\right)$} & \multicolumn{3}{|c|}{ Secondary $\left(n^{o}\right)$} \\
\hline & Nudes & Leaves & Clusters & Stem & Leaves & Clusters \\
\hline VSP1 & $12.5 \mathrm{~b}$ & $11.0 \mathrm{~b}$ & 2.4 & $11.0 \mathrm{~b}$ & $27.4 \mathrm{~b}$ & 2 \\
\hline S1 & $18.5 \mathrm{a}$ & $17.2 \mathrm{a}$ & 2.2 & $13.4 \mathrm{a}$ & $37.4 \mathrm{a}$ & 1.7 \\
\hline $\mathrm{S} 2$ & $20.1 \mathrm{a}$ & $19.7 \mathrm{a}$ & 2.1 & $11.2 \mathrm{~b}$ & $21.6 \mathrm{~b}$ & 0 \\
\hline $\operatorname{EEM}^{1}(n=8)$ & 1.4 & 1.67 & 0.22 & 1.02 & 3.15 & 0.54 \\
\hline Sig $^{2}$ & $*$ & $*$ & ns & $*$ & $* *$ & ns \\
\hline
\end{tabular}

${ }^{1}$ EEM: standard average error for $n=8$ samples per treatment.

${ }^{2}$ Sig: significant differences; ns, * and $* *$ means to there is no significant differences or $P<0.05$ and $P<0.01$ respectively. The values with the same letter are equal (T. Duncan). $P$-values were determined by analysis of variance.

Differences among treatments were clear within $20-30 \mathrm{~cm}$ (Table 3). VSP1 scored the highest values and these differences were mainly shown at $20-30 \mathrm{~cm}$ of soil level. At levels deeper than $0.4 \mathrm{~m}$, the soil kept its original structure and revealed no differences between treatments, so no statistical differences were found.

S2 seems to explore deeper than the other two treatments (lower crop load) the soil profile in order to obtain more water, making a real improve about the use of its root system.

\subsection{Dry matter partitioning}

Differences in solar interception should explain the increase in yield due to a better use of natural resources [15]. Dry matter results were calculated according to different parts of the vine (Table 4). Leaves (number and weight) from principal shoots were higher in S2 and S1 compared with VSP1 (+5 g/shoot) and within the same crop load, sprawl system was higher too. It means that sprawl systems could reach bigger active leaves than VSP system, giving more photo assimilates to the plant due to principal shoots are usually more active than secondary shoots during the growth cycle. S1 scored highest values in clusters weight and number. S2 showed the crop load effect, causing a less secondary shoot development compared to S1 and VSP1 $(<15-45 \%$ respectively). It should be noted that is not easy to find secondary clusters in S2 systems.

Referring to the main crop load effect, higher load treatment (S2) had more clusters (per m) and therefore, a yield increment of $16 \%$ in comparison with the others treatments. On the other hand, S2 showed lower average bunch weight (from 17.0 to $22.5 \%$ ) and a reduced number of berries (from 12 to $21 \%$ ) and low berry weight (from 4.4 to $9.2 \%$ ) per cluster, but this it was balanced by higher cluster number per vine (from 32 to $35 \%$ ).

Therefore, with an increment of load, the berry size will decrease but the number of berries will increase, which has direct effect on total yield and produces, at same time, an increase in skin/flesh ratio during harvest.

Table 5. Yield partitioning for three treatments.

\begin{tabular}{|c|c|c|c|c|c|}
\hline \multirow[b]{2}{*}{ Treatment } & \multicolumn{5}{|c|}{ Yield partitioning 2006} \\
\hline & $\mathbf{N}^{0}$ Clusters $\cdot \mathbf{m}^{-1}$ & Yield $\left(\mathrm{kg} \cdot \mathrm{m}^{-2}\right)$ & $\begin{array}{c}\text { Cluster average } \\
\text { weight (g) }\end{array}$ & $\begin{array}{c}100 \text { Berries } \\
\text { average weight (g) }\end{array}$ & $\mathbf{N}^{0}$ berries $\cdot$ cluster $^{-1}$ \\
\hline VSP1 & $24.68^{b}$ & $1.73^{\mathrm{b}}$ & $190.42^{\mathrm{a}}$ & $111.34^{\mathrm{a}}$ & $171.19^{\mathrm{a}}$ \\
\hline S1 & $23.82^{\mathrm{b}}$ & $1.71^{\mathrm{b}}$ & $195.10^{\mathrm{a}}$ & $104.57^{\mathrm{b}}$ & $187.34^{\mathrm{a}}$ \\
\hline $\mathrm{S} 2$ & $36.20^{\mathrm{a}}$ & $2.05^{\mathrm{a}}$ & $153.24^{\mathrm{b}}$ & $101.05^{\mathrm{c}}$ & $152.06^{\mathrm{b}}$ \\
\hline $\operatorname{EEM}^{1}(n=40)$ & 0.60 & 0.04 & 6.09 & 0.08 & 1.02 \\
\hline $\mathrm{Sig}^{2}$ & $* *$ & $* *$ & $* *$ & $* *$ & $* *$ \\
\hline
\end{tabular}

${ }^{1}$ EEM: standard average error for $n=40$ samples per treatment.

${ }^{2}$ Sig: significant differences; ${ }^{*}$ means to there is significant differences with $P<0.01$. The values with the same letter are equal (T. Duncan). $P$-values were determined by analysis of variance. 
Table 6. Must composition for three treatments.

\begin{tabular}{|c|c|c|c|c|c|c|}
\hline \multirow[b]{2}{*}{ Treatment } & \multicolumn{6}{|c|}{ Must Composition 2006} \\
\hline & ${ }^{\mathbf{o}}$ Brix & pH & $\begin{array}{c}\text { Acidity }(\mathrm{g} \text { ac } \\
\text { tartaric/L) }\end{array}$ & IPT & $\begin{array}{l}\text { Total Antocian } \\
\text { content }\left(\mathbf{m g} \cdot \mathbf{L}^{-1}\right)\end{array}$ & $\begin{array}{l}\text { Antocian extractables } \\
\left(\mathbf{m g} \cdot \mathbf{L}^{-1}\right)\end{array}$ \\
\hline VSP1 & 25.1 & 3.5 & 5.9 & 46.7 & $1470,35 b$ & 794.33 \\
\hline $\mathrm{S} 1$ & 25.9 & 3.5 & 5.2 & 54.7 & $1804,34 \mathrm{a}$ & 936.95 \\
\hline $\mathrm{S} 2$ & 25.8 & 3.5 & 5.2 & 52.7 & $1903,30 \mathrm{a}$ & 983.94 \\
\hline $\begin{array}{c}\operatorname{EEM}^{1}\left(n_{1}=8 \text { and }\right. \\
\left.n_{2}=4\right)\end{array}$ & 0.76 & 0.02 & 0.46 & 2.54 & 81.28 & 76.94 \\
\hline $\mathrm{Sig}^{2}$ & ns & ns & ns & ns & $*$ & ns \\
\hline
\end{tabular}

${ }^{1}$ EEM: standard average error for $n=8$ samples per treatment.

${ }^{2}$ Sig: significant differences; ns, and $*$ means to there is no significant differences or $P<0.05$ respectively. The values with the same letter are equal (T. Duncan). $P$-values were determined by analysis of variance.

\subsection{Yield components, berry sampling and juice analysis}

Leaves and cluster microclimate are the key factors for determining the acidity content, $\mathrm{pH}$ and $\mathrm{K}$ of must and consequently, wine composition [16]. No differences were obtained during 2006 for Brix degree, acidity and pH values (Table 6). Data from total and extractable anthocyanin content reflect the effect of increasing shading clusters area in the final berry synthesis of anthocyanins, which is very useful in winemaking process [17]. It should be noted that cv. Syrah is very sensitive to the changes in thermal effects during total anthocyanins synthesis. This effect causes differences in berry anthocyanins content, which are heavier in extremely hot conditions (2006), reaching around 20\% in open and non-positioned free systems.

Finally, crop load does not change must composition notably, but it increase total plant yield because it provides more clusters. These are less exposed to sunlight, and with this training system, the degradation of anthocyanins at the end of ripening can be prevented. The effect of the load is less important than the use of open training system, which modify light and thermal microclimate through spatial distribution of vegetation and shading effects in the plant, increasing phenolic and anthocyanic berry content.

\section{Conclusion}

Sprawl system demands higher amount of water in soil profile because its root system growth deeper benefiting more from the available water capacity. This fact is evident inside grapevine root zone $(20-50 \mathrm{~cm})$, despite upper soil levels. Crop load has a relevant effect in order to increase these water consumption differences.

Water plant status is usually reflected by leaf water potential. S2 has lower daily values during the whole cycle due to the crop load increment, which produces a higher demand from the leaves (more total surface area). Water stress increases not only with the crop load, but also with a higher canopy exposure.

Surface area is less time exposed with open and nonpositioned systems (S1 and S2) comparing with vertical systems (VSP1), so VSP1 should suffers the water deficit before sprawl systems, within the same environmental conditions [16]. However, its stomatal closure occurs soon after due to the lower total leaf surface exposed, causing a less consumption of soil water availability.

Therefore, under a severe water demand due to extreme environmental conditions, the irrigation gets increased the water potential in plants (usually higher for all treatments) and its recovery is more pronounced in sprawl system than VSP. When weather conditions are not so limiting, the water demand for the S1 and VSP1 are equal, having S2 the lower potential values due to the higher crop load.

Double effect due to non-positioned open system (sprawl) and crop load increment may mitigate the light over exposure (bunches and leaves) to solar direct radiation, avoiding undesirable over ripening and dehydration berry effects, but with a real improve in vegetative and reproductive yield to the plant (dry matter results).

Free and non-positioned systems can help improving not only the plant microclimate, but also anthocyanic berry composition without any other relevant change in must composition, allowing yield increase (if there is enough water available in plant-soil system).

The present work shows that in warm climates and with the same amount of water (168 $\mathrm{mm}$ and $248 \mathrm{~mm}$ for rainfall and irrigation respectively), sprawl system resulted in better plant microclimate for these trial conditions, mainly improving the exposure of leaves and clusters, maximizing the internal canopy ventilation, increasing the vegetative growth and yield; without disrupting main berry quality parameters, and even increasing phenolic and anthocyanic berry content.

The authors gratefully acknowledge the effort of Osborne Distribuidora S.A. company for technical and financial support on the implementation of this project (MEC, IDI: P030260221). The author did the works during its research formation at U.P.M. (2004-2008).

\section{References}

[1] FAO. Towards a water and food secure future. Critical Perspectives for Policy-makers. 69, pp. (2015).

[2] Sebastian, B., Baeza, P., Santesteban, L. G., de Miguel, P. S., De La Fuente, M., \& Lissarrague, J. R. Response of grapevine cv. Syrah to irrigation frequency and water distribution pattern in a clay soil. Agricultural Water Management, 148, 269-279, (2015). 
[3] Comas L. H., Eissenstat D.M. and A.N. Lakso. Assessing root death and root system dynamics in a study of grape canopy pruning. New Phytol. 147, 171-178. (2000).

[4] Carbonneau, A. and P. Costanza. Response of vine leaf water potential to quick variation in canopy exposure. Example of canopy opening manipulation of Merlot (Vitis vinifera L.). J. Int. Sci. Vigne Vin. 38. 27-33 (2004).

[5] Van Huyssteen L., The grapevine root and its environment. Department of agriculture and water supply, pp. 44-54. (1988).

[6] Bergqvist J., Dokoozlian N., Ebusida N.. Sunlight exposure temperature effects on berry growth and compositon of Cabernet-Sauvignon and Grenache in the Central San Joaquin Valley of California. Am.J.Enol. Vitic. 52(1), 1-7, (2001).

[7] Spayd S.E., Tarara .J.M., Mee D.L., Ferguson J.C. Separation of sunlight and temperature effects on the composition of Vitis vinifera cv. Merlot berries. American Journal of Enology and Viticulture (53). 171-182, (2002).

[8] Comas L. H., Andersson L.J., Dunst R.M., Lakso A.N. and Eissenstat D.M. Canopy and environmental control of root dynamics in a long-term study of Concord grape. New Phytol. 167, 829-840. (2005).

[9] Deloire A., Carbonneau A., Ojeda $\mathrm{H}$ and Z. Wang. La vigne et l'eau. Journal International des Sciences de la Vigne et du Vin. 38. 1-13 (2004).

[10] Williams, L. E., and F. J. Araujo. Correlations among predawn leaf, midday leaf, and midday stem water potential and their correlations with other measures of soil and plant water status in Vitis vinifera. Journal of the American Society for Horticultural Science $127.3448-454$ (2002).

[11] Williams, L. E., and P. Baeza. Relationships among ambient temperature and vapor pressure deficit and leaf and stem water potentials of fully irrigated, fieldgrown grapevines. American Journal of Enology and Viticulture 58.2. 173-181 (2007).

[12] Saxton, K.E. and W.J Rawls. Soil water characteristic estimates by texture andorganic matter for hydrologic solutions. Soil Sci. Soc. Am. J. 70, 1569-1578 (2006).

[13] Van Leeuwen, C., Tregoat, O., Chone, X., Bois, B., Pernet, D., Gaudillere, J.P. Vine water status is a key factor in grape ripening and vintage quality for redBordeaux wine. How can it be assessed for vineyard management purposes? J.Int. Sci. Vigne Vin. 43, 121-134 (2009).

[14] Dufourcq, T; L. Gontier; E. Serrano y N. Ollat. Leaf area and crop yield ratio: Effects on vine water status, must quality, wine quality for four varieties trained in south-west France. Progrès Agricole et Viticole. 122. 503-507. (2005).

[15] De la Fuente, M; P. Baeza; P. Sánchez de Miguel and J.R. Lissarrague. Relation between exposed leaf surface, level of intercepted radiation and overall yield of plants. $33^{\text {rd }}$ OIV World Congress of Vine and Wine. 8th General Assembly of the OIV, 20-25 June 2010, Tbilisi, Georgia. 13 pp. (2010).

[16] De la Fuente, M. R. Linares; P. Baeza and J. R. Lissarrague. Importance of canopy porosity into vineyard and the relationship with the grape maturity. Digital estimation method. Ciência e Técnica Vitivinícola. 28, and Proc. of 18th International GiESCO Symposium, 633-638p (2013).

[17] Haselgrove L., Bottinf D., Heeswijck R., Rod P. B., Dry P., Ford C. and P.G. Illand. Canopy microclimate and berry composition: the effect of bunch exposure on the phenolic composition Vitis vinifera L. cv Shiraz grape berries. Aus. J. Grape and Wine Research 6: 141-149 (2000). 